\title{
AGGLUTINATION IN PERTUSSIS
}

\author{
ITS CHARACTERISTICS AND ITS COMPARATIVE VALUE IN CLINICAL DIAG- \\ NOSIS, AND IN DETERMINATION OF GENUS AND SPECIES *
}

\author{
OLGA R. POVITZKY, M.D. \\ ASSISTED BY \\ EDWARD WORTH \\ NEW YORK
}

\section{INTRODUCTION}

The work herewith reported is part of a series of studies on pertussis begun by the Bureau of Laboratories of the New York City Health Department in 1914 under direction of Dr. A. W. Williams. ${ }^{1}$ The subject of agglutination was taken up chiefly because of the different reports given by various authors as to the value of agglutination and of complement fixation in the early clinical diagnosis of pertussis, and because of the comparatively few definite reports made on the value of former test.

\section{CRITICAL STATEMENT OF PREVIOUS FACTS}

All authors (at least those who give some details about their work) are agreed that agglutinins for $B$. pertussis may be produced in most test animals but statements are vague as to the time and amounts of production and the condition under which they are produced.

The general statement is usually made that after several inoculations made preferably into the peritoneal cavity, the serum of the animal showed agglutinins. The reports on the strength of the serum, if stated at all, is varied. Thus Bordet and Gengou ${ }^{2}$ obtained in rabbits after four inoculations intraperitoneally a serum which the authors say was not as strong as that of the horse which was inoculated many more times subcutaneously and intravenously. Arnheim ${ }^{3}$ obtained a serum in rabbits of 1 to 5,000 strength and in the horse 1 to 10,000 , but he gave no details of methods and times of inoculation. Wollstein ${ }^{4}$ by

* Submitted for publication Oct. 21, 1915.

* From the Research Laboratory, Health Department, New York City.

1. Williams, Anna Wessels: The Etiology of Pertussis, Arch. Pediat., 1914, xxxi, No. 8.

2. Bordet, J., and Gengou: Note Complementaire sur le microbe de la coqueluche, Ann. d. l'Inst. Pasteur, 1907, xxi, 720.

3. Arnheim, Georg: Ueber den gegenwartigen stand der Keuchhustenfrage, Berl. med. Wchnschr., 1908, xlv-II, 1453.

4. Wollstein. Martha: The Bordet-Gengou Bacillus of Pertussis, Jour. Exper. Med., 1909, xi, 41. 
intraperitoneal inoculations obtained a serum in the rabbit up to 1 to 800. Intravenous inoculations were not successful. No details of amounts or time of inoculation are given. Bächer and Menschikoff, Shiga, Imai, Euguchi ${ }^{6}$ found agglutination tests in pertussis of no value, as their bacillary emulsions were self-agglutinating.

Wollstein, ${ }^{4}$ Frankel, ${ }^{7}$ Seiffert, ${ }^{8}$ Arnheim, ${ }^{3}$ found agglutination tests of some value in clinical diagnosis of pertussis. Renaux ${ }^{9}$ did not think it worth while to try.

Bordet $^{10}$ finds it of value only under certain conditions, namely, the organism must be freshly isolated from human sputum and grown on rich blood medium. The work of Bordet on agglutination will be dwelt on more in detail later.

\section{ORIGINAL WORK}

Our studies may be divided into the following:

1. The determination of the best conditions under which agglutinating serum may be obtained in test animals.

2. The comparative value of the test in demonstrating specificity of strains isolated by us from human beings suffering from whooping cough.

3. To add further evidence as to the comparative value of complement fixation and agglutination in the clinical diagnosis of pertussis.

1. The Production of Agglutinins.-Rabbits, horses, goats and sheep were used by us in producing agglutinins. Rabbits and horses responded more readily than the goats and sheep, so most of the tests have been made with serums from the former animals. Practically all of the rabbits inoculated (over 95 per cent.) which have remained in good health have produced abundant agglutinins for $B$. pertussis, though not all equally abundant.

Antigens Used.-We have worked with twenty-seven strains of culturally and morphologically typical Bordet-Gengou bacilli ( $B$. pertussis), with nine strains of $B$. influenzae, with four strains of $B$. bronchisepticus, and with four

5. Bächer, St., and Menschikoff, V. K.: Ueber die aetiologische Bedeutung des Bordetschen Keuchhustenbacillus und den Versuch einer Spezifischen Therapie der Pertussis, Centralbl. f. Bact., 1911, 1 Abt. Orig., 1xi. No. 3, p. 218.

6. Shiga, X., Imai, N., and Euguchi, Ch.: Eine Modifation fur Bordet Gengou's Nahrborden fur die Keuchhustenbacillen nebst einige ergebnissen in Serologishen Beziehung, Centralbl. f. Bact., etc., 1913, 1 Abt. Orig., 1xix, 104.

7. Fraenkel, C.: Untersuchungen zur Entstehung des Keuchhusten, München. med. Wchnschr., 1908, 1v, 1683.

8. Seiffert, G.: Ueber den Bordetschen Keuchhustenbacillus, München. med. Wchnschr., 1909 , p. 1561.

9. Renaux. E.: Le microbe de Bordet et Gengou agent etiologique de la coqueluche, Centralbl. f. Bact., etc., 1914, 1 Abt. Orig., 1xxr, No. 3. 197.

10. Bordet, J.: Note Complementaire sur le microbe de la coqueluche et sa variabilite au point de vue du serodiagnostic et de la toxicite. Centralbl. f. Bact. 1912, Abt. 1, Orig., 1xvi, Parts 2-4, p. 276. 
strains of bacilli morphologically similar to $B$. pertussis, but with cultural differences. These strains we call pertussis-like bacilli. Living emulsions were used for the regular inoculations. In the rabbit, antigen extracts similar to those used in the complement fixation test were also tested, as were regular vaccines and sensitized vaccines, for their power to produce agglutinins.

Living cultures of $B$. Pertussis for inoculations were prepared by scraping off a forty-eight-hour culture grown on tube slant on Bordet-Gengou medium in recently isolated cultures, and on coagulated horse blood glycerin veal agar in older strains, and emulsifying in normal salt solution. The dose was graduated according to age of the culture from isolation and to the kind of culture medium used.

The highest virulence for guinea-pigs has been one-half slant of a profuse culture inoculated intraperitoneally. This initial virulence on the blood-vealagar medium became less after the culture had been grown in successive transplants on this medium for a year. Then one or two slants on coagulated horse blood agar were required to kill a guinea-pig of about 200 strains inoculated intraperitoneally.

The living cultures of influenza bacilli were grown for forty-eight hours on coagulated horse blood agar and then scraped off and emulsified in normal salt solution.

The initial dose of $B$. pertussis and of $B$. infuenzae inoculated intraperitoneally into rabbits was from one-eighth to one-half slant. The last dose was five to six cultures on 100 c.c. Blake bottles.

The pertussis-like strains were all on plain veal agar, on which medium they grow abundantly. The emulsions were made in the same way as the others. These strains were very virulent for rabbits, one especially, No. 31, which had to be given at first in doses of $1 / 100$ to $1 / 50$ of a slant. The last dose was four slants.

The antigen extracts were prepared in the same manner as were those for complement fixation tests: namely, a forty-eight-hour growth of $B$. pertussis on coagulated horse-blood-veal-agar medium was scraped off in distilled water, shaken for two successive days, brought up in the water bath to $56 \mathrm{C}$. and left in the incubator at the same temperature over night; the next day the emulsion was centrifuged and the supernatant fluid rendered isotonic by adding 9 per cent. of salt and was injected into the animals.

The dosage of this antigen was $1 / 4$ c.c. intravenously, $1 / 2$ c.c. intraperitoneally, or 1 c.c. subcutaneously. The dose was gradually increased up to 10 c.c. The toxicity of this antigen was tested and it was found that 5 to 10 c.c. of it killed guinea-pigs $200 \mathrm{gm}$. in weight, inoculated intraperitoneally, in twenty-four hours; 3 c.c. had no effect.

The vaccines were made by scraping a forty-eight-hour growth of $B$. pertussis on coagulated horse blood veal agar, emulsifying in physiologic salt solution, shaking the emulsion for two successive days and then heating it at $56 \mathrm{C}$. for one and one-half hours. The initial dosage of the vaccine, which was usually 15 billions per cubic centimeter strong, was $1 / 4$ c.c. intravenously, $1 / 2$ c.c. intraperitoneally, or 1 c.c. subcutaneously. Its toxicity was such that 10 c.c. of a 15 billion strong vaccine killed guinea-pigs of about $200 \mathrm{gm}$. weight, inoculated intraperitoneally, in twenty-four hours; 3 to 5 c.c. had no effect.

The sensitized raccines were prepared the same way as the killed vaccines, except that they were shaken only one day, and instead of being heated were agglutinated by 1:100 immune pertussis serum for one hour in the incubator at $37 \mathrm{C}$. and were then placed in the ice-box over night. The next day the precipitated emulsion was shaken up (the supernatant fluid is quite clear) and washed two to three times in physiological salt solution. The dosage of this vaccine was the same as of the killed one, but it was usually 10 instead of 15 billions per c.c. strong. Its lethal dosage is still being tested in order to gain more explicit data about the comparative virulence of living and sensitized pertussis 
organisms. Thus far we have found that 1:40 immune rabbit pertussis serum added to 3 c.c. of a 10 billion per c.c. strong vaccine prevents the death of $200 \mathrm{gm}$. guinea-pigs, while the control mixtures of normal rabbit serum added to the same amount of emulsion killed the pigs by the next day. The emulsions of nonsensitized bacilli in 1 c.c. doses killed the pigs in twenty-four hours. The sensitized vaccine organisms remain alive in the ice-box for two to three weeks. when the growth gradually decreases; on the fifth week only a few colonies are obtained. The untreated organism lives in the ice-box about two months. More work is being done on the bacterial toxicity of these immune serums.

Technic of Agglutination Tests.-It is of vast importance to obtain homogeneous emulsions, especially for microscopic tests. The importance of the culture medium and the subsequent treatment of the cultures for agglutination tests has thus far never been dwelt on in detail by any writer on this subject, except perhaps Bordet ${ }^{11}$ himself, and then only on some phases of it. B. pertussis when recently isolated grows only on Bordet-Gengou medium, but after five to six generations, it grows much more abundantly and characteristically on glycerin veal agar 0.4 acid to phenolphthalein, to which horse's blood ( 1 to 75 to 1 to 100 ) has been added while the agar is very hot (90). The influenza bacillus also grows excellently on this medium. with the exception that the reaction should be neutral to phenolphthalein. Though the pertussis organism grows equally well on the neutral medium, it forms an adherent growth which cannot be separated from the medium and the acid reaction seems to prevent this occurrence. The cultures for the tests are taken from a forty-eight-hour growth on this acid medium and allowed to grow for twenty-four hours on 1 to 100 coagulated horse blood veal agar neutral in reaction. A twenty-fourgrowth usually is not adherent on neutral medium in the first generation from the acid medium. The glycerin is omitted for the last growth, as it seems to interfere with the reaction. Recently isolated strains, of course, must be grown on Bordet-Gengou medium. The growth is scraped off, not washed off, in distilled water and shaken in an electrical shaker for three to four hours. A standard emulsion is kept in the ice-box, so that the emulsions are always uniform. The serums are diluted with 0.85 per cent. salt in 1 to $10,25,50,100$, 200, 400 parts, etc. Each test tube contains 1/4 c.c. of the diluted serum and $3 / 4$ c.c. of the emulsion, the final dilution being $1: 4$. The tests are macroscopic witl the animal serum and microscopic with patient's serums unless there is enough serum for the macroscopic test. The test tubes and hanging drops are put in the incubator at $37 \mathrm{C}$. for one to two hours and readings made; the macroscopic tests are left over night in the ice-box. Complete agglutination is designated by ++ ; incomplete by + ; slight by \pm .

With this technic we have not as yet encountered a self-agglutinating strain on coagulated horse-blood-veal-agar medium and only in the very beginning a few recently isolated strains on Bordet-Gengou medium were slightly self-agglutinating (perhaps they were not shaken long enough). The glassware must be absolutely clean and antiseptics such as mercury chlorid avoided. For the examination of patients' serums, one or more strains of $B$. pertussis of known agglutinability and one influenza strain are used. One recently isolated strain is grown on rich Bordet-Gengou medium (according to the suggestion from Bordet); the other on our standard medium (coagulated horse

11. Bordet, J., and Sleeswyk: Serodiagnostic et variabilite des microbes suivant le milieu de culture, Ann. d. l'Inst. Pasteur, 1910, xxiv, 476 . 
blood veal agar). The last medium as a rule gives the most satisfactory results, especially for hanging drops, as it invariably forms a homogeneous mass of entirely separated organisms, and when a reaction occurs it is quite unmistakable.

First Appearance of Agglutinins.-Agglutinins, as a rule, did not begin to appear in the rabbit until after the sixth or seventh inoculation; at least in no higher strength than $1: 40$ or $1: 100$. After that, if the animal kept well, the agglutinins continued to rise with each inoculation. Most rabbits were sacrificed when they showed from 2,400 to 5,000 titer, which happened usually after the tenth to the twelf th inoculation. Some of them might possibly have shown a higher titer if further inoculated.

Normal rabbits show agglutination in dilution not higher than $1: 25$; sheep and goats $1: 40$ to $1: 100$; horses up to 100 . The sheep and goats seemed to respond more slowly to the inoculations than the rabbits and horses, so they were dropped. Two of the three horsesone by intravenous, the other by subcutaneous inoculation-showed agglutinins up to 2,000 after the third and fourth inoculation. Two horses are still in the process of immunization.

The injection of living cultures intraperitoneally seems to be most conducive to the development of agglutinins in the rabbit, though now and then there is a rabbit found which shows fairly good agglutinations after four to six inoculations. With killed vaccines, sensitized vaccines and antigens, the titer has never become as high as with living cultures.

Some of the rabbits inoculated with killed vaccines and more of those inoculated with sensitized vaccines and antigens (eight to nine inoculations each) did not develop agglutinins to any extent, though they were markedly immune. Thus, five of such rabbits were injected with four to five surface growths of 100 c.c. bottles without ill effects, while the control rabbits died from the same dose or less (three bottles) the same day or next morning from acute toxemia. Two rabbits, more responsive to the vaccines, developed after a few inoculations a comparatively high agglutination titer-up to 1,000. The low titer rabbits were inoculated later with living cultures, and after a few inoculations showed a high agglutinating power. The influenza rabbits did not form agglutinins as readily as did the pertussis rabbits, and the titer never reached higher than 1 to 1,600 . The accompanying table shows the comparative rise of agglutinins and of complement fixing bodies in rabbits inoculated with $B$. pertussis, $B$. influenza and pertussis-like bacilli.

2. Specificity of Strains from Whooping Cough Cases.-From Table 3 , which shows the agglutinative reaction of pertussis serums 
TABle 1.-Comparative Rise of Agglutinins and Complement Fixation Antibodies, withINTRAPERITONEAL-

\begin{tabular}{|c|c|c|c|c|c|c|c|c|c|}
\hline \multirow{2}{*}{$\begin{array}{l}\text { Ini- } \\
\text { tial } \\
\text { Wt. } \\
\text { Gm. }\end{array}$} & \multirow[t]{2}{*}{$\begin{array}{l}\text { Last } \\
\text { Wt. } \\
\text { Gm. }\end{array}$} & \multirow{2}{*}{$\begin{array}{c}\text { Initial } \\
\text { Dose }\end{array}$} & \multirow{2}{*}{$\begin{array}{l}\text { Last } \\
\text { Dose }\end{array}$} & \multirow{2}{*}{ Strain } & $\begin{array}{c}\text { After } 3 \mathrm{~d} \\
\text { Inoculation }\end{array}$ & $\begin{array}{l}\text { After 4th } \\
\text { Inoculation }\end{array}$ & $\begin{array}{l}\text { After 5th } \\
\text { Inoculation }\end{array}$ & $\begin{array}{l}\text { After 6th } \\
\text { Inoculation }\end{array}$ & $\begin{array}{c}\text { After 7th } \\
\text { inoculation }\end{array}$ \\
\hline & & & & & \begin{tabular}{|l|l} 
Agglut. & C. F.
\end{tabular} & Agglut. C. F. & Agglut. C. F. & Agglut: C. F. & Agglut. C. F. \\
\hline
\end{tabular}

PERTUSSIS RABBITS

\begin{tabular}{|c|c|c|c|c|c|c|c|c|c|c|c|c|c|c|}
\hline 1,920 & 1,840 & $1 / 2$ slant & 3 slants...... & P. D. & $t$ & .001 & $1: 40$ & .0003 & Rabb & sacrif & ed afte & four i & oculatic & \\
\hline 2,400 & $2,670 \mid$ & $1 / 4$ slant & $\begin{array}{l}\text { Surface grown } \\
\text { of } 3-100 \text { c.e. } \\
\text { bottles }\end{array}$ & 55 & 0 & 0 & 0 & o & 0 & .005 & $\dagger$ & .003 & 1,200 & .002 \\
\hline 1,420 & 1,780 & $1 / 8$ slant & $\begin{array}{l}\text { Surface grown } \\
\text { of } 4-100 \text { c.e. } \\
\text { bottles }\end{array}$ & 93 & 0 & .005 & 0 & .004 & 0 & .003 & 0 & .001 & $\dagger$ & .0009 \\
\hline 1,380 & 1,750 & $1 / 4$ slant & $\begin{array}{l}\text { Surf ace grown } \\
\text { of } 4-100 \text { c.c. } \\
3 \text { bottles }\end{array}$ & 110 & 0 & .004 & 0 & 0 & 0 & .005 & $t$ & .0004 & 400 & .0007 \\
\hline 2,040 & 1,880 & $\begin{array}{l}1 \text { slant } \\
\text { on plain } \\
\text { vea } 1 \\
\text { agar }\end{array}$ & $\begin{array}{l}\text { Surface grown } \\
\text { of } 4-100 \text { c.e. } \\
12 \text { bottles }\end{array}$ & P. D. & 0 & 0 & 0 & 0 & 40 & 0 & 1,200 & .001 & $\stackrel{2}{2}, 000$ & .004 \\
\hline 1,345 & 1,565 & $1 / 4$ slant & $\begin{array}{l}\text { Surface grown } \\
\text { of } 4-100 \text { c.c. } \\
4 \text { bottles }\end{array}$ & 154 & 0 & 0 & 0 & 0 & 0 & 0 & 0 & 0 & 0 & 0 \\
\hline 1,870 & 2,300 & $1 / 2$ slant & $\begin{array}{l}\text { Surface grown } \\
\text { of } 4-100 \text { c.c. } \\
9 \text { bottles }\end{array}$ & 55 M93 & 0 & 0 & 0 & 0 & 200 & 0 & 1,000 & .001 & 2,000 & .005 \\
\hline 1,700 & 2,130 & $\begin{array}{l}\text { Sensitiz- } \\
\text { ed } \nabla a c- \\
\text { cine } 1 / 4 \\
\text { e.c. }{ }^{1 / 4}\end{array}$ & 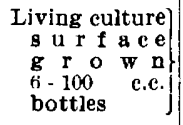 & $\left.\begin{array}{l}154 \\
155 \\
163\end{array}\right\}$ & 0 & 0 & 0 & 0 & 40 & 0 & $\dagger$ & .02 & 200 & .002 \\
\hline ],950 & 2,110 & $\begin{array}{l}\text { Extract } \\
\text { "ant } i- \\
\text { gen" } 1 \\
\text { c.c. }\end{array}$ & 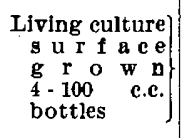 & $\left\{\begin{array}{l}154 \\
155 \\
163\end{array}\right\}$ & 0 & 0 & 0 & 0 & 0 & 0 & 0 & 0 & 0 & 0 \\
\hline 2,670 & 2,730 & $\begin{array}{c}\text { Killed } \\
\text { vaccine } \\
1 / 4 \quad \text { c.c. }\end{array}$ & 8 c.c.............. & $\left\{\begin{array}{l}154 \\
155 \\
163\end{array}\right\}$ & 0 & .003 & 0 & $\dagger$ & 400 & .002 & 1,600 & .0005 & & \\
\hline
\end{tabular}

INFLUENZA RABBITS

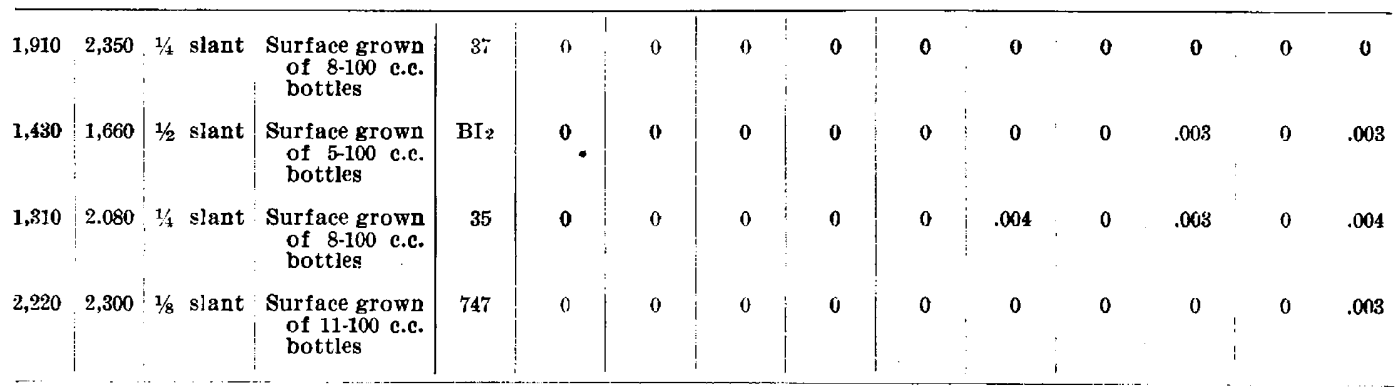

RABBitS INOCULATED WITH PERTUSSIS-LIKE BACILlUS

\begin{tabular}{|c|c|c|c|c|c|c|c|c|c|c|c|c|c|c|c|}
\hline 1,905 & 1,710 & $1 / 50$ slant & $31 / 2$ slants..... & 31 & $!$ & 0 & .004 & 0 & .008 & 0 & .005 & 0 & .009 & $t$ & .000 \\
\hline 1,980 & 2,365 & $1 / 8$ slant & 6 slants........ & c. & i & 0 & 0 & 0 & .005 & 0 & 0 & 0 & .006 & 0 & .007 \\
\hline 1,565 & 1,620 & $1 / 8$ slant & 1 slant......... & 1 & ; & $t$ & $t$ & 1,200 & .0006 & \multicolumn{2}{|c|}{ Sacrificed } & & & & \\
\hline
\end{tabular}

* Injections with living cultures were given once a week; vaccines and antigens were given twice a week till the sixth inoculation, then once a week.

+ Not tested.

+ After injection with living cultures intraperitoneally. 
-Successive Inoculations of B. Pertussis, B. Influenzae and Pertussis-Like Bacillus by -INJECTIONS

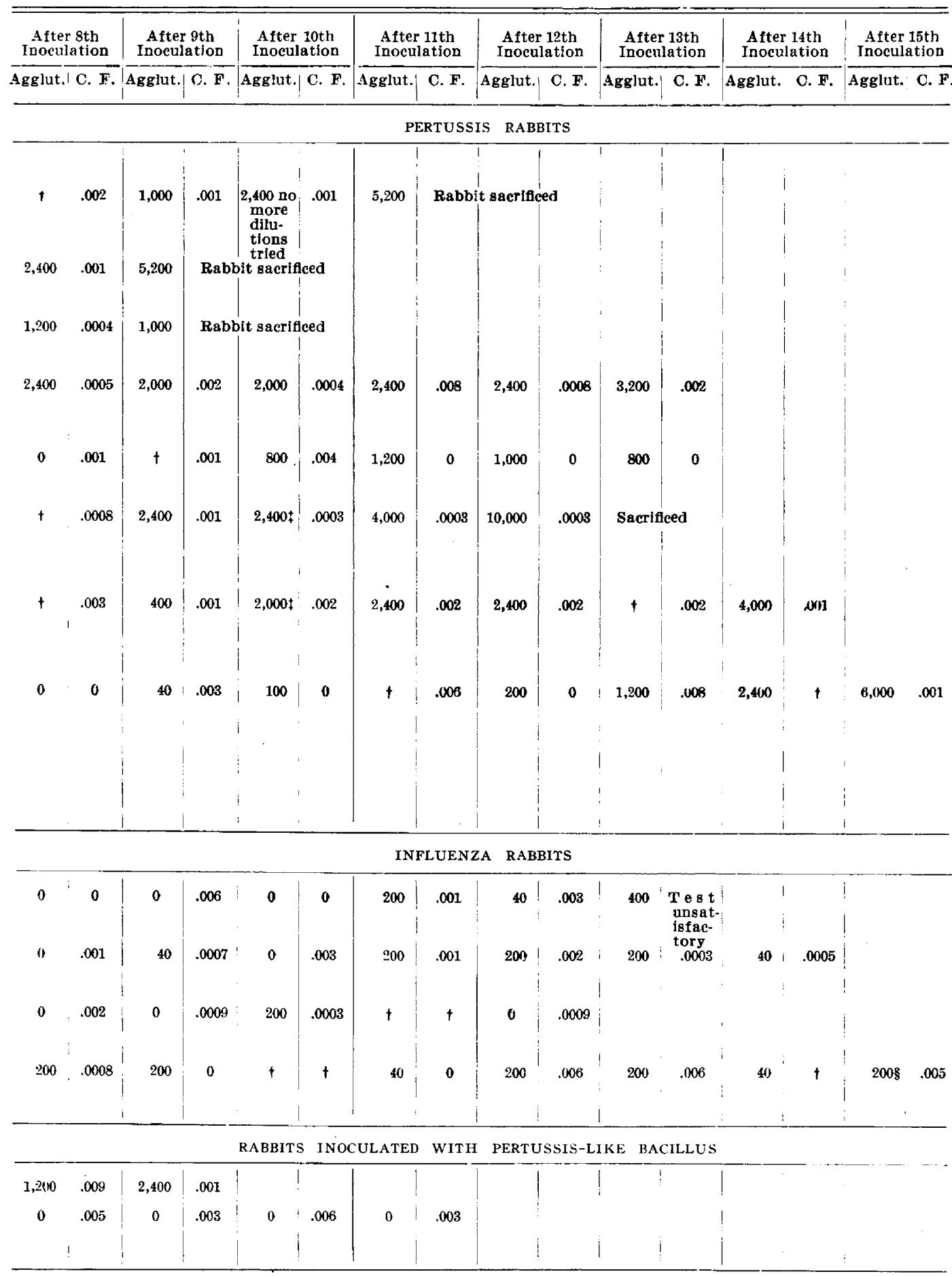

S After the seventeenth inoculation this rabbit reacted up to 1:1600; after the eighteenth inoculation it dropped down to 1:400; at the end of the twenty-first inoculation the reaction was only 1:200. Complement fixation varied from 0.0008 to 0.0001

I Subeutaneously.

Downloaded From: http://archinte.jamanetwork.com/ by a New York University User on 05/11/2015 
TABle 2.-Agglutination Tests of Pertussis Serum with Homologous and Heterogeneous Strains-B. Influenza, Pertussis-Like Bacillus AND B. BRONCHISEPTICUS

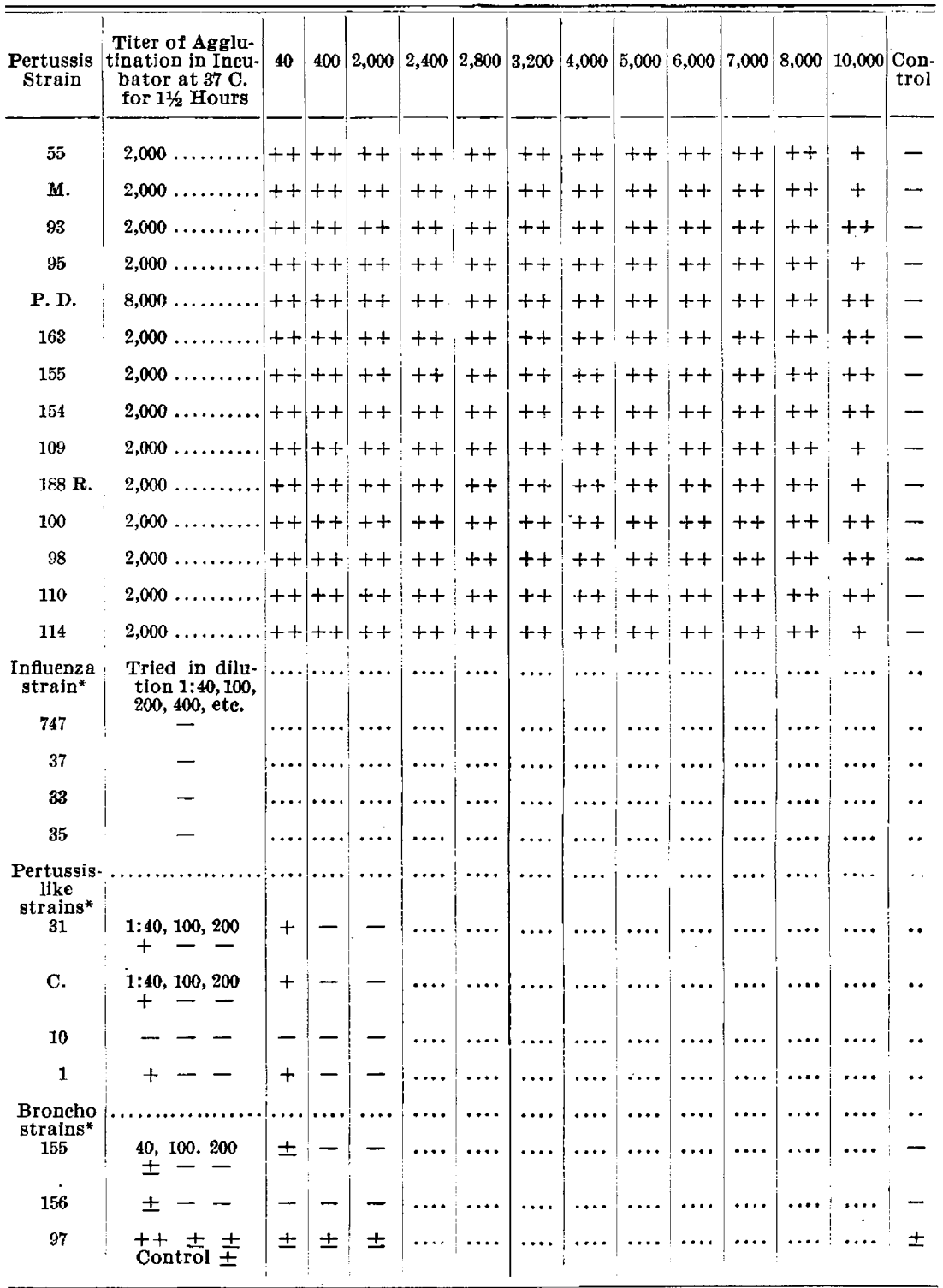

* Pertussis serum. 
with heterogeneous strains and attempt at cross agglutination with $B$. influenza, and pertussis-like bacilli, it would seem that not only do the pertussis strains show no relationship to the pertussis-like strains or to the influenza strains, but that all strains of typical pertussis bacilli belong to one group. This is in marked contrast to the reaction of influenza serums which agglutinate most heterogeneous strains in very low dilutions or not at all. The pertussis-like organisms also show a variation in strains. Thus of the four strains tried, No. 31 and No. 1 seem to be identical. The others seem to be quite distinct strains. In

TABle 3.-Patients' Pertussis Sera

\begin{tabular}{|c|c|c|c|c|c|c|c|c|c|c|c|}
\hline \multirow[b]{2}{*}{ Weeks Whoop } & \multicolumn{3}{|c|}{ Agglutination } & \multicolumn{2}{|c|}{ Reactions } & \multirow[b]{2}{*}{ Weeks Whoop } & \multicolumn{5}{|c|}{ Complement-Fixation Tests } \\
\hline & $\begin{array}{c}\text { No. } \\
\text { of } \\
\text { Cases }\end{array}$ & - & $1: 40$ & $1: 100$ & $1: 200$ & & $\mid \begin{array}{c}\text { No. } \\
\text { of } \\
\text { Cases }\end{array}$ & - & + & ++ & +++ \\
\hline I & 13 & 5 & 4 & .. & 4 & $I$ & 6 & 4 & 0 & 1 & 1 \\
\hline 2 & 10 & 0 & 6 & 3 & 1 & 2 & 4 & 3 & 0 & 0 & 1 \\
\hline 3 & 9 & $i$ & 0 & 6 & 2 & 3 & 5 & 0 & 2 & 2 & 1 \\
\hline 4 & 13 & 2 & 4 & 6 & 1 & 4 & 2 & 0 & 1 & 0 & 1 \\
\hline 5 & 2 & 1 & 0 & 0 & 1 & 5 & 4 & 1 & 0 & 1 & 2 \\
\hline 6 & 4 & 0 & 4 & $\theta$ & 0 & 7 & 2 & 2 & 0 & 0 & 0 \\
\hline 14 & 1 & 0 & 0 & 1 & 0 & 17 & I & 0 & 0 & 0 & 1 \\
\hline 20 & 1 & 1 & 0 & 0 & 0 & Convalescent 8 & 1 & .. & .. & .. & 1 \\
\hline Convaleseent 1 & 2 & 1 & 0 & 1 & $\cdots$ & $\begin{array}{l}\text { Convalescent } \\
5 \text { mos. }\end{array}$ & 1 & .. & .. & .. & 1 \\
\hline Convalescent 8 & 1 & 1 & .. & .. & .. & $\ldots \ldots \ldots \ldots$ & .. & $\cdots$ & $\cdots$ & $\cdots$ & $\cdots$ \\
\hline $\begin{array}{c}\text { Convalescent } \\
5 \text { yrs. } \\
\text { Exposed to } \mathrm{W} .0 . \\
2 \text { weeks }\end{array}$ & 1 & $\begin{array}{l}1 \\
.\end{array}$ & $\begin{array}{l}\cdots \\
2\end{array}$ & .. & $\begin{array}{l}\cdots \\
.\end{array}$ & …... & $\begin{array}{l}\cdots \\
\cdots\end{array}$ & .. & .. & $\begin{array}{l}\cdots \\
\cdots\end{array}$ & . \\
\hline $\begin{array}{c}\text { Control sera, } \\
\text { adults }\end{array}$ & 58 & 29 & 19 & 10 & .. & $\ldots \ldots \ldots \ldots \ldots$ & 51 & 49 & 2 & .. & $\cdots$ \\
\hline $\begin{array}{l}\text { Control sera, } \\
\text { ehildren (scarlet } \\
\text { fever) }\end{array}$ & 10 & 6 & 4 & $\because$ & *. & ............ & $\because$ & $\cdots$ & $\cdots$ & .. & $\cdots$ \\
\hline
\end{tabular}

no instance is there cross agglutination of $B$. pertussis serum with $B$. influen $z a$, even in 1:40. The serum of the pertussis-like bacilli and the influenza serums sometimes agglutinate $B$. pertussis in $1: 40$, but never higher. Of the four strains of $B$. bronchisepticus used, none showed any relationship to pertussis agglutinins. The variability of hemoglobinophilic strains has been shown by previous work. ${ }^{12}$ Absorp-

12. Povitzky, Olga R.: Tests of Hemoglobinophilic Bacilli from Conjunctivitis in Regard to Their Virulence and Their Agglutinating Properties, Collected Studies, 1913-1914. 
tion tests verified the supposition gained from the straight agglutination tests, that all pertussis strains belong to one species as far as agglutination reactions are concerned. In order to do these tests, the serum must be saturated by a very thick emulsion, as the least agglutinin not absorbed may be shown markedly by sensitive strains more agglutinable than others, and in this way, obscure the test. One rabbit was inoculated with three strains which we thought might be a little different from each other on account of their varied powers to agglutinate in weak serums, but by absorption tests they proved to have identical agglutinins for themselves as well as for all the other strains ${ }^{10}$ tested.

Variations in Agglutinability of Pertussis Strains.--Though all pertussis strains are practically equally agglutinated by a strong serum, individual strains vary in regard to promptness of response, and with a weak serum heterogeneous strains may show marked difference in the quantity of serum required for a reaction. We have often seen the phenomenon observed by Bordet and others, of the agglutination of heterogeneous strains more strongly than the strain with which the antiserum was obtained. This characteristic of $B$. pertussis is brought out more clearly by weak serum. Thus, some of our serums from rabbits and goats, after a few inoculations, hardly agglutinated their homologous strains, while they agglutinated a heterogeneous strain up to 1 to 2,000. It is important, therefore, in testing patients serums to use a strain of known agglutinability (as in typhoid).

The difference in the agglutinability of different pertussis strains was well brought out in the instance of one of our rabbits inoculated with three strains, M., 55 and 93 . After five inoculations, its serum agglutinated strains 93 and $\mathrm{M}$. and the heterogeneous strain P. D. up to 200, but not at all Strain 55. After six inoculations, M., 93 and $P$. D. were agglutinated up to 2,000 , and 55 only very slightly in the first few dilutions. After the ninth inoculation, 55 was agglutinated up to 200 , while the other strains showed very strong agglutination up to 2,400. After the tenth inoculation, all four strains (M., 55, 93, P.D.) showed very strong agglutination up to 2,400 (no more difutions were tried). After eleven inoculations, all strains were agglutinated up to 4,000 (no higher dilutions tried). After the twelfth inoculation, agglutinins for all three hemologous strains and twelve other strains tried were 1 to 10,000 in a trial serum. It would seem that only a very strong serum could overcome the sluggishness of Strain 55. Another strain of this kind is No. 163. Rabbits inoculated with 155, 154 and 163 showed very high agglutination with both Strains 154 and 155 before 163 was agglutinated. 
Another interesting feature in the agglutinations of $B$.pertussis is that when a mixture of strains is used in making the emulsions for agglutination, the reaction occurs more promptly than when each strain is used alone. Why this occurs we do not yet know. Because of it, we are making comparative tests with a mixture of three or more pertussis strains in emulsion and a one-strain emulsion for testing patients' serums.

According to Bordet, ${ }^{10}$ the age of a culture from date of isolation influences the agglutinating property of $B$. pertussis. He cites an experiment in which he tested a pertussis serum stored in the ice-box for four years with its homologous strain kept transplanted all these years on Bordet-Gengou medium. No agglutination occurred though this strain was highly agglutinated by the same serum four years ago. The natural conclusion at first was that the serum had lost its potency, but when it was tested with a freshly isolated strain it gave a strong agglutinating reaction. Bordet, therefore, advocates for testing patients' serums for agglutination to use freshly isolated cultures grown on rich blood medium.

In our experience we have found that while freshly isolated strains on Bordet-Gengou medium are quite responsive to a strong serum, the most readily agglutinable strains are a few that were isolated one to one and one-half years ago, and which grow best at present on our standard coagulated horse-blood-veal-agar medium. Of course we cannot predict how much modified these strains may be in four years.

Relationship of Culture Mediums to Agglutination.--Bordet ${ }^{11}$ states that animals inoculated with $B$. pertussis grown on BordetGengou medium develop agglutinins for $B$. pertussis grown only on the same medium, not for the organism grown on plain agar, and vice versa. He also states that by absorption tests he found that these two agglutinins were not the same.

In testing these experiments, we worked with three mediums: Bordet-Gengou, coagulated horse-blood-veal-agar, and plain veal-agar (only two of our strains grow well on plain agar thus far). When working with weak serums (serums which do not give a prompt reaction in the incubator at one and one-half hours, though they may agglutinate up to 2,400 the next morning) and freshly isolated strains, we were impressed by the truth of Bordet's statements. Thus Horse 1 , injected three times with two strains grown on Bordet-Gengou medium, did not agglutinate the same strains grown on coagulated horse blood veal agar, but agglutinated these very strains up to 2,000 when they were grown on Bordet-Gengou medium; but the same serum agglutinated our older agglutinable strain grown on coagulated horse blood veal agar in just as high dilutions. On the other hand, a rabbit 
inoculated with a well agglutinable strain grown on plain veal agar after six to seven inoculations, agglutinated up to 2,000 equally well the same strain grown on each of the three mediums. Absorption tests did not seem to bear out the statement that the agglutinins were different. From our experience it would seem that the culture medium influences an agglutinable strain in so far as it affects its growth and best development, not in its production of different kinds of agglutinins. The recent strains grow well only on Bordet-Gengou medium and are, therefore, more agglutinable on this medium than when grown on coagulated horse blood veal agar, on which they grow in the beginning very scantily. The sluggish strains which grow well on either medium seem to be influenced by the culture mediums when tested with weak serums. Thus, the serum of the same horse injected with cultures on Bordet-Gengou medium, which agglutinated an easily agglutinable old strain on coagulated horse blood veal agar, did not agglutinate a sluggish strain on the same medium (though it grows on it profusely) but agglutinated it when it was grown on Bordet-Gengou medium.

A strong serum, therefore, in our experience, agglutinated equally well, though may be not equally promptly, all strains, sensitive and sluggish, no matter on what medium grown.

Comparative Value of Complement Fixation and Agglutination Tests in the Differentiation of Strains.--Agglutinins as a rule (as mentioned before) did not begin to show in the rabbit in any marked degree till after the sixth or seventh inoculation, while complement fixation antibodies, as seen from the accompanying table, usually appeared after the fourth inoculation, but also showed a higher titer after the eighth to ninth inoculation. Though complement fixation and agglutination outside of the time limit ran quite parallel, namely, most of the animals which show high complement titer show also strong agglutinins, there were rabbits which showed high complement titer and no agglutination, and at times vice versa. Especially was this the case when the rabbit showed a very high complement titer after a few inoculations. Thus Rabbit 28 inoculated with $B$. pertussis, after the fourth inoculation showed a complement titer of 0.0003 , and agglutination only $1: 40$. On the other hand, Rabbit 92 showed complement titer of 0.001 while it agglutinated up to 5,200. Many influenza rabbits showed a high complement titer and very little or no agglutination. On the whole, however, agglutinins in pertussis rabbits, though produced more slowly, were produced more regularly and more surely than were complement-fixing substances.

From our observations we conclude that the agglutination of $B$. pertussis by artificially produced immune serum gives a more clearcut differentiation from pertussis-like bacilli and from hemoglobino- 
philic bacilli than does complement fixation which shows a cross fixation in low dilutions with some of these latter organisms (Olmstead and Povitzky ${ }^{13}$ ).

3. The Comparative Value of Agglutination and Complement Fixation in the Clinical Diagnosis of Pertussis.--Serums from 59 cases of pertussis in various stages of the disease were tested for agglutinins. These results, also the results of control serums of adults suffering from different diseases, and of children with scarlet fever are given in Table 3.

We see by this table that we cannot depend on agglutination as a positive guide to diagnosis in dilutions up to 1 to 100 . If, however, the reaction at 1 to 100 is very prompt (in an hour at 37 C.) and complete, it may be considered suspiciotis, since in none of the controls did the reaction recorded occur quickly. When a reaction occurs in dilutions of 1 to 200 , it indicates a probable recent infection with $B$. pertussis.

Unfortunately, we did not always get enough serum from patients to test both agglutination and complement fixation, so our comparative table is not of the same cases, but the series of those tested for complement fixation is taken from those quoted in the paper of $\mathrm{Olm}$ stead and Luttinger ${ }^{14}$ that did not receive vaccines. According to this tabulation, a positive specific complement fixation did not occur quite as frequently in the first week as did agglutination at 1 to 200 . On the other hand, out of fifty-one control serums of adults, only two showed a positive reaction by complement fixation while about 33 per cent. showed a reaction up to $1: 40$ by agglutination tests and about 17 per cent. showed a reaction $1: 100$. Control children serums showed in 40 per cent. a reaction in $1: 40$.

Only three out of the fifty-nine pertussis serums showed agglutination with $B$. influenzae, two in $1: 40$ and one in $1: 200$ in the first week of the whoop.

The control serums showed agglutination with $B$. influenzae only in two cases in $1: 40$, while complement fixation showed fixation with influenza quite frequently.

\section{SUM MARY}

1. A strongly agglutinating pertussis serum was best obtained in the rabbit by ten to twelve intraperitoneal inoculations of living cultures given at seven-day intervals. Over 95 per cent. of rabbits; inoculated in this manner, produced agglutinins, though not in equal abun-

13. Olmstead, Miriam P., and Povitzky, Olga R.: The Complement Fixation of Bordet-Gengou Bacillus, Jour. Med. Research, 1915.

14. Olmstead, Miriam P., and Luttinger, Paul: Complement Fixation in Pertussis, The Archives Int. Med., 1915, xvi, 1. 
dance. Agglutinins are also produced by vaccines, but not as abundantly as by living cultures. Those rabbits which received eight to nine inoculations of vaccine and did not show agglutinins to any large extent, were, nevertheless, markedly immune.

A high titer serum (from 1:4,000 to $1: 10,000$ ) always proved to be a quickly acting serum which reacted in from one to one and one-half hours in the incubator at $37 \mathrm{C}$., sometimes up to $1: 8,000$, with well agglutinable pertussis strains.

A low titer serum was usually slow in reaction and did not show agglutination till after remaining in the ice-box over night.

2. By agglutination tests, $B$. pertussis strains can be specifically identified from hemoglobinophilic bacilli, pertussis-like bacilli, and $B$. bronchisepticus. In no instance was there cross agglutination between these organisms-at least not higher than 1:40. For identification a strong serum of high titer should be used.

3. By these tests it would also seem that all pertussis strains isolated in our laboratory belong to one group. A strong serum agglutinated all our pertussis strains (twenty-seven in number) equally well though not equally promptly in the highest dilution. Absorption tests (tried in seven most variable strains), proved the supposition gained by the straight agglutination tests.

4. The variation of the agglutinability of pertussis strains with weaker serums depends very much on the age of the culture (dating from isolation) and culture medium. Freshly isolated strains are best agglutinable on Bordet-Gengou medium; older strains on our standarc? coagulated blood veal agar.

6. A strong serum agglutinates equally well, though not equally promptly, all strains, no matter on what medium grown and how sluggish the strain is.

6. Agglutination tests in clinical diagnosis of pertussis compares favorably with complement fixation only in the first week of the whoop. In the later stages of the disease complement fixation antibodies appear more frequently than agglutinins.

7. Thirty-three per cent. of adult nonpertussis serums show agglutination in up to $1: 40 ; 17$ per cent. in up to 100 ; 40 per cent. of children's nonpertussis serums (scarlet fever cases) showed a reaction in up to $1: 40$. A dilution of not less than $1: 200$ is necessary for a practically positive diagnosis of pertussis by agglutination test. 